\title{
Analisa Kecacatan Produk Baling-Baling Blower pada Proses Chasting Menggunakan Metode Seven Tools di CV. Anugerah Abadi
}

\author{
Sofiyanurriyanti \\ Program Studi Teknik Industri, Sekolah Tinggi Teknik Qomaruddin Gresik \\ email: sofiyanurriyanti20@gmail.com
}

DOI: http://dx.doi.org/10.21107/rekayasa.v12i1.5310

\begin{abstract}
ABSTRAK
Terdapat lima kecacatan dalam pembuatan baling-baling blower U-8 yaitu cacat berlubang, permukaan kasar, retak, kekasaran meluas dan deformasi. Kecacatan yang dialami sebesar 1204 produk atau 20,27\% dari jumlah produksi. Permukaan kasar merupakan jenis cacat yang mempunya tingkat kecacatan terbesar yaitu 53,08\% dari total kecacatan atau sebanya 627 produk. Untuk mengurangi cacat produk baling-baling blower U-8 harus difokuskan pada jenis kecacatan permukaan kasar. Untuk mengurangi jenis kecacatan tersebut operator harus lebih teliti dalam melakukan pemeriksan cetakan pasir, bahan baku aluminium juga harus bersih dan sebagian dari bahan ingot (batangan), campuran pasir cetak harus diperhatikan, kondisi lingkungan harus menerapkan 5P dan menambah fasilitas kerja( lampu penerangan), pergantian alat seperti mold dan penambahan pengkur suhu pada tungku peleburan.
\end{abstract}

Kata Kunci: metode seven tools, cacat produk, proses produksi

\section{ABSTRACT}

\section{Analysis of Blower Blacker Product Reality in Chasting Process} Using Seven Tools Method in CV. Anugerah Abadi

There are five defects in the manufacture of $U-8$ blower blades which are hollow defects, rough surfaces, cracks, widespread roughness, and deformation. Defects experienced by 1204 products or $20.27 \%$ of total production. The rough surface is a type of defect that has the biggest disability rate of 53.08\% of the total disability or Seba 627 products. To reduce the defects of the U-8 blower products should be focused on the types of rough surface defects. In order to reduce the type of disability the operator must be more careful in examining the sand mold, the aluminum raw material must also be clean and part of the ingot material (bar), the mixture of printed and must be considered, the environmental conditions must apply 5P and add work facilities (lighting) replacement tools such as mold and the addition of temperature drier to the melting furnace. Keywords: seven tools method, product defect, production process

\section{PENDAHULUAN}

CV. Anugerah Abadi adalah sebuah usaha yang bergerak dibidang industri manufaktur. Produk utama yang dihasilkan CV. Anugerah Abadi adalah logam alumunium dengan berbagai varian bentuk dan ukuran seperti baling-baling blower, roda rol kabel, impeller dan cetakan kue. Didalam persaingan pasar tentu mutu/kualitas produk sangat diperlukan untuk kepuasan customer. Sehingga perlu adanya sistem yang mampu mengendalikan kualitas produk secara konsisten. CV. Anugerah Abadi masih menerapkan sistem pengendalian kualitas dengan coba-coba (trial error) dan cenderung tidak sistematis serta asal-asalan semata. Faktor-faktor yang berpengaruh

\section{Article History:}

Received: Maret 2019; Accepted: April 2019

ISSN: 2502-5325 (Online) Terakreditasi Peringkat 4 oleh

Kementerian Riset, Teknologi dan Pendidikan Tinggi (ARJUNA),

berdasarkan Keputusan Direktur Jenderal Penguatan Riset dan

Pengembangan Nomor: 21/E/KPT/2018 tanggal 9 Juli 2018 terhadap proses produksi baik antara lain faktor bahan, mesin, lingkungan maupun sumber daya manusianya. Sehingga berdampak pada jumlah produk cacat yang semakin tinggi. Pengoptimalan faktor-faktor tersebut dapat mengurangi jumlah produk cacat, yang pada akhirnya akan menghasilkan produk yang bermutu baik dari segi kualitasnya maupun kuantitasnya. Dari tingkat kerusakan (cacat) produk yang semakin kecil, maka dapat mengoptimalkan keuntungkan perusahaan. Dengan demikian perlu adanya upaya untuk mengimplementasikan sistem Pengendalian Mutu Terpadu (PMT). Salah satu produk yang menempati permintaan konsumen tertinggi pada UD. Bina Usaha adalah baling-baling blower tipe U-8 yang mencapai kurang lebih

\section{Cite this as:}

Sofiyanurriyanti, S. (2019). Analisa Kecacatan Produk Baling-Baling Blower pada Proses Chasting Menggunakan Metode Seven Tools di CV. Anugerah Abadi. Rekayasa, 12(1), 66-70. doi:http://dx.doi.org/10.21107/rekayasa.v12i1.5310 (C) 2019 Universitas Trunojoyo Madura 
6000 pcs. Karena pekerja yang cukup sedikit dan dituntut tepat waktu, sehingga berpengaruh pada proses produksi yang cenderung terburu-buru. Pengetahuan sumber daya manusianya masih kurang memumpuni ditambah dengan peralatan yang masih sangat tradisional. Hal ini berdampak pada produk yang dihasilkan mengalami kecacatan seperti produk berlubang, permukaan kasar, retakan pada produk, kekasaran. Tujuan penelitian ini adalah cara mengidentifikasi jenis-jenis dan tingkat kecacatan produk pada proses produksi logam aluminium, dan mengurangi cacat produk pada proses produksi logam aluminium di dengan metode seven tools.

\section{METODE PENELITIAN}

Pada metode penelitian dilakukan di CV. Anugerah Abadi yang berada di wilayah Jawa Timur terletak di daerah Desa Bungah Kabupaten Gresik. Metode pengumpulan data dalam penelitian dilakukan pada teknik pengambilan sampel, dimana jenis data yang digunakan adalah data primer dengan cara melakukan observasi dan wawancara pada pihak manajemen dan karyawan perusahaan sedangkan dan data sekunder diperoleh dengan melalui data yang telah diteliti. Penerapan metode untuk memecahkan masalah yang timbul mengenai permasalahan kualitas diperlukan suatu alat bantu untuk menganalisis masalah. Alat bantu yang dikembangkan adalah seven tools antara lain (Baroto T, 2002):

\section{Lembar Periksa (Check Sheet)}

Lembar pencatatan data secara mudah dan sederhana, sehingga menghindari kesalahan yang mungkin terjadi, dalam pengumpulan data.

2. Histogram

Diagram batang yang berfungsi untuk menggambarkan bentuk distribusi sekumpulan data yang biasanya berupa karakteristik mutu. 3. Diagram Pareto

Suatu diagram atau grafik dengan menjelaskan urutan prioritas perbaikan untuk mengatasi permasalahan.

\section{Stratifikasi}

Pengelompokkan stratifikasi berdasarkan (data kerusakan, fenomena, sebab akibat) kedalam kelompok karateristik yang sama.

5. Diagram Tebar (Scatter Diagram)

Suatu diagram yang menggambarkan hubungan antara dua faktor dengan memplot data dari kedua faktor tersebut dari suatu arafik.

$$
r_{x y}=\frac{\mathrm{N} \sum \mathrm{xy}-\sum \mathrm{x} \sum \overline{\mathrm{y}}}{\sqrt{\left.\left[\mathrm{N} \sum\left(\mathrm{x}^{2}\right)-\sum\left(\mathrm{x}^{2}\right)\right] \mathrm{x}\left[\mathrm{N} \sum\left(\mathrm{y}^{2}\right)\right]-\sum\left(\mathrm{y}^{2}\right)\right]}}
$$

\section{Peta Kendali (Control Chart)}

Control Chart adalah alat pengendalian proses berupa grafik untuk menentukan batas kendalai atas (lupper limit control) dan batas kontrol bawah (lower limit control).

Perhitungan control chat:

$$
\begin{aligned}
& \mathrm{C}=\frac{\Sigma N}{n} \\
& \mathrm{UCL}=\mathrm{C}+3 \sqrt[2]{C} \\
& \mathrm{LCL}=\mathrm{C}-3 \sqrt[2]{C}
\end{aligned}
$$

Keterangan:

$\mathrm{N}=$ Jumlah produk cacat

$\mathrm{n}=$ Banyaknya periode

$C=$ Rata-rata kerusakan

$\mathrm{UCL}=$ Batas kontrol atas

$\mathrm{LCL}=$ Batas kontrol bawah

7. Diagram Tulang Ikan (Fishbone DiagramDiagram Sebab Akibat)

Suatu diagram yang digunakan untuk mencari unsur penyebab yang diduga dapat menimbulkan masalah tersebut atau disebut diagram tulang ikan.

\section{HASIL DAN PEMBAHASAN}

Sistem produksi di CV. Anugerah Abadi adalah production to order,artinya produksi yang dilakukan hanya berdasarkan pesanan dari cutomer. Jadi sebelum proses produksi dilakasanakan perushaan akan mengkaji terlebih dahulu pesanan yang diajukan oleh pelanggan baik itu spesifikasi, harga, jumlah maupun waktu penyelesaian Data Hasil Produksi dapat ditunjukkan pada Tabel 1.

Tabel 1. Data Hasil Produksi

\begin{tabular}{ccc}
\hline No & Bulan & Jumlah Produksi (pcs) \\
\hline 1 & Januari & 450 \\
2 & Februari & 500 \\
3 & Maret & 400 \\
4 & April & 480 \\
5 & Mei & 500 \\
6 & Juni & 650 \\
7 & Juli & 530 \\
8 & Agustus & 550 \\
9 & September & 500 \\
10 & Oktober & 380 \\
11 & November & 450 \\
12 & Desember & 550 \\
& Jumlah & 5940 \\
\hline
\end{tabular}

Sumber : CV. Anugerah Abadi, 2017

Setelah dilakukan pemeriksaan dan melihat buku rekap cacat produk, yang dihasilkan lebih dari $20 \%$ dari jumlah produk yang diproduksi. Dengan demikian perlu adanya perbaikan secara berkelanjutan. Setelah dilakukan pemeriksaan juga dapat 5 jenis cacat yang dialami oleh produk baling-baling blower U-8 yai- 
68 | Sofiyanurriyanti, Analisa Kecacatan Produk Baling-Baling Blower...

Tabel 2. Data Jumlah Produk Cacat

\begin{tabular}{lccccccc}
\hline & \multicolumn{7}{c}{ Jenis-Jenis Kecacatan } \\
\cline { 3 - 8 } Bulan & $\begin{array}{c}\text { Jumlah Pro- } \\
\text { duksi (pcs) }\end{array}$ & $\begin{array}{c}\text { Berlubang } \\
\text { (pcs) }\end{array}$ & $\begin{array}{c}\text { Permukaan } \\
\text { Kasar } \\
\text { (pcs) }\end{array}$ & $\begin{array}{c}\text { Retak } \\
\text { (pcs) }\end{array}$ & $\begin{array}{c}\text { Kekasaran } \\
\text { Meluas } \\
\text { (pcs) }\end{array}$ & $\begin{array}{c}\text { Deformasi } \\
\text { (pcs) }\end{array}$ & $\begin{array}{c}\text { Jumlah Keca- } \\
\text { catan } \\
\text { (pcs) }\end{array}$ \\
\hline Januari & 450 & 7 & 45 & 3 & 5 & 25 & 85 \\
Februari & 500 & 5 & 15 & 1 & 11 & 14 & 46 \\
Maret & 400 & 13 & 101 & 10 & 17 & 40 & 40 \\
April & 480 & 7 & 57 & 7 & 10 & 30 & 30 \\
Mei & 500 & 1 & 45 & - & 13 & 9 & 9 \\
Juni & 650 & 5 & 55 & 4 & 21 & 18 & 18 \\
Juli & 530 & 9 & 76 & 2 & 24 & 25 & 25 \\
Agustus & 550 & 7 & 19 & 7 & 17 & 23 & 23 \\
September & 500 & 4 & 91 & 11 & 34 & 21 & 21 \\
Oktober & 380 & 5 & 37 & 5 & 10 & 17 & 17 \\
November & 450 & 1 & 27 & - & 8 & 25 & 25 \\
Desember & 550 & 5 & 59 & 6 & 19 & 16 & 16 \\
Jumlah & 5940 & 69 & 627 & 56 & 189 & 263 & 263 \\
\hline
\end{tabular}

Sumber : CV. Anugerah Abadi, 2017

tu cacat berlubang, permukaan kasar, retak, kekasaran meluas dan deformasi.

Pengolahan Data

Setelah data kecacatan diperoleh, maka analisa dan pengolahan data dapat dilakukan dengan mengunakan metode seven tools:

\section{Check Sheet}

Dari data yang telah diperoleh dibuat check sheet jumlah dan jenis kerusakan. Data yang dikumpulkan yaitu data produk cacat dari produk baling-baling blower U-8. Check sheet kerusakan pada tahun 2017.

\section{Histogram}

Dari tabel check sheet maka dapat dibuat histogram yang menggambarkan jumlah kerusakan produk setiap bulannya. pada gambar 1 tampak histogram kerusakan produk pada tahun 2017.

3.

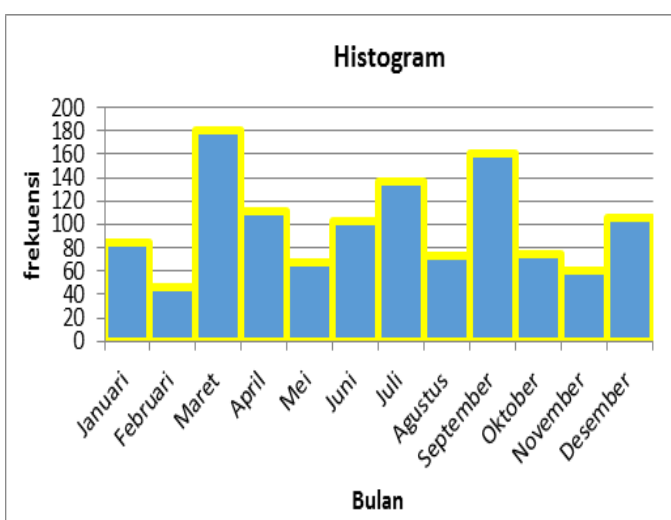

Gambar 1 . Histogram
(Sumber : Data diolah CV. Anugerah Abadi, 2017)
Permukaan Kasar $=627 / 1204 \times 100 \%=52,08 \%$ Deformasi $=263 / 1204 \times 100 \%=21,84 \%$

Kekasaran Meluas $=189 / 1204 \times 100 \%=15,70 \%$ Berlubang $=69 / 1204 \times 100 \%=5,73 \%$

Retak = 56/ $1204 \times 100 \%=4,65 \%$

Dapat dilihat pada Gambar 2. Digaram Pareto bahwa jenis kerusakan yang paling besar adalah kerusakan Permukaan Kasar dan jenis kerusakan yang paling kecil adalah Retak. Menurut aturan pareto (aturan 80-20) untuk perhitungan korelasi antara kerusakan adalah hanya untuk kerusakan Permukaan Kasar.

\section{$4 . \quad$ Stratifikasi}

Perbandingan kerusakan yang akan dibuat scatter diagram adalah dua keruskan yang memiliki nilai terbesar. Perbandingan jerusakan tersebut dapat dilihat pada tabel 3.

\section{$5 . \quad$ Scatter Diagram}

Korelasi antara jumlah kerusakan bermata/ berlubang dan pecah tengah yang terjadi dapat dilakukan dengan menggunakan scatter diagram. Data untuk perhitungan koefisien korelasi antara kerusakan permukaan kasar ( $\mathrm{x}$ ) dan deformasi (y).

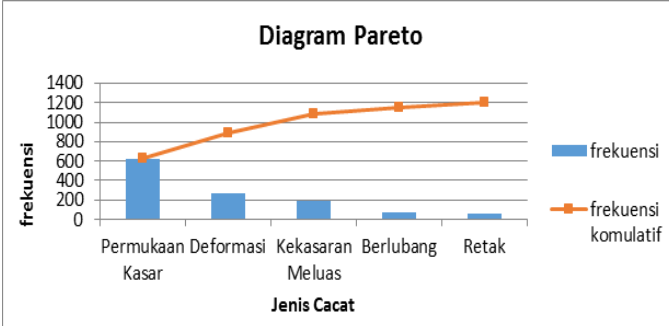

Gambar 2. Diagram Pareto

(Sumber : Data diolah CV. Anugerah Abadi, 2017) 
Tabel 3. Stratifikasi Jumlah Kerusakan Permukaan Kasar dan Deformasi

\begin{tabular}{lcc}
\hline Bulan & $\begin{array}{c}\text { Permukaan } \\
\text { Kasar } \\
\text { (pcs) }\end{array}$ & $\begin{array}{c}\text { Deformasi } \\
\text { (pcs) }\end{array}$ \\
\hline Januari & 45 & 25 \\
Februari & 15 & 14 \\
Maret & 101 & 40 \\
April & 57 & 30 \\
Mei & 45 & 9 \\
Juni & 55 & 18 \\
Juli & 76 & 25 \\
Agustus & 19 & 23 \\
September & 91 & 21 \\
Oktober & 37 & 17 \\
November & 27 & 25 \\
Desember & 59 & 16 \\
Jumlah & 627 & 263 \\
\hline
\end{tabular}

Sumber : Data diolah CV. Anugerah Abadi, 2017

Tabel. 4 . Data Perhitungan Koefisien Korelasi Kerusakan Permukaan Kasar dan Deformasi.

\begin{tabular}{llllll}
\hline Bulan & $\begin{array}{l}\text { Permu- } \\
\text { kaan } \\
\text { Kasar } \\
\text { (pcs) }\end{array}$ & $\begin{array}{l}\text { Defor- } \\
\text { masi } \\
\text { (pcs) }\end{array}$ & $\mathrm{x}^{2}$ & $\mathrm{y}^{2}$ & $\mathrm{xy}$ \\
\hline Januari & 45 & 25 & 2025 & 625 & 1125 \\
Februari & 15 & 14 & 225 & 196 & 210 \\
Maret & 101 & 40 & 10201 & 1600 & 4040 \\
April & 57 & 30 & 3249 & 900 & 1710 \\
Mei & 45 & 9 & 2025 & 81 & 405 \\
Juni & 55 & 18 & 3025 & 324 & 990 \\
Juli & 76 & 25 & 5776 & 625 & 1900 \\
Agustus & 19 & 23 & 361 & 529 & 437 \\
September & 91 & 21 & 8281 & 441 & 1911 \\
Oktober & 37 & 17 & 1369 & 289 & 629 \\
November & 27 & 25 & 729 & 625 & 675 \\
Desember & 59 & 16 & 3481 & 256 & 944 \\
Jumlah & 627 & 263 & 40747 & 6491 & 14976 \\
\hline
\end{tabular}

Dari data stratifikasi dapat dibuat gambar scatter diagram seperti pada Gambar 3.

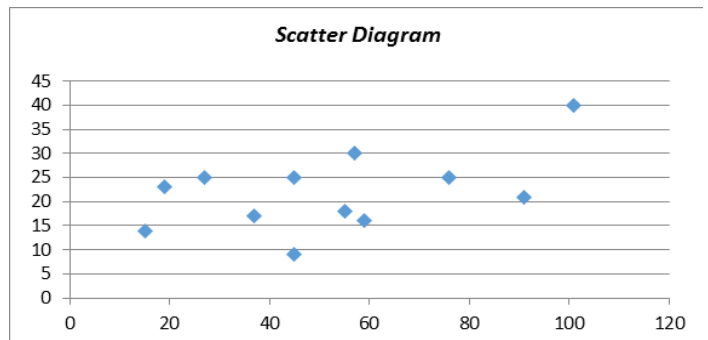

Gambar 3. Scatter Diagram Jenis Kerusakan Permukaan Kasar dan Deformasi
(Sumber : Data diolah CV. Anugerah Abadi, 2017) 6. Diagram Sebab Akibat

Dari pareto diagram terlihat bahwa jumlah kerusakan terbesar adalah cacat permukaan kasar. Dengan demikian akan dilakukan analisa penyebab kerusakan tersebut dengan menggunakan cause and effect diagram.

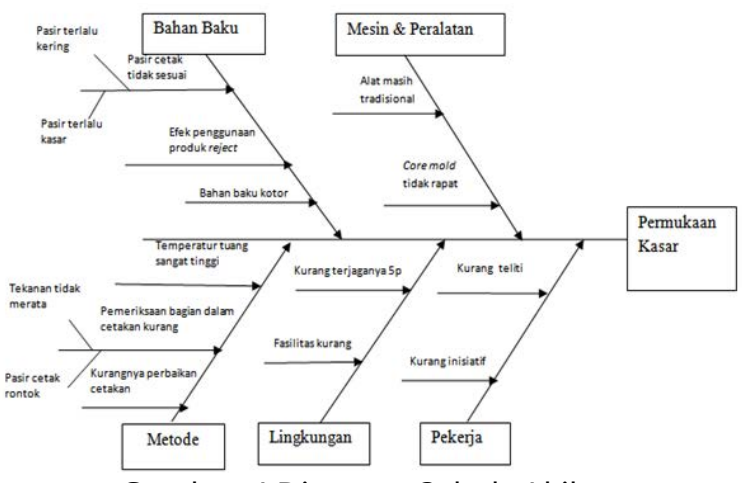

Gambar 4.Diagram Sebab Akibat

(Sumber: Data diolah CV. Anugerah Abadi, 2017)

$7 . \quad$ Control Chart

Rata-rata kerusakan $(\mathrm{C})=\Sigma \mathrm{N} / \mathrm{n}$

$$
\begin{aligned}
& =1204 / 12 \\
& =100,33 \mathrm{pcs}
\end{aligned}
$$

Batas kontrol atas $(\mathrm{UCL})=\mathrm{C}+3 \sqrt{ }(2 \& \mathrm{C})$

$$
\begin{aligned}
& =100,33+3 \\
& =100,33+30,05
\end{aligned}
$$$$
=130,38 \mathrm{pcs}
$$

Batas kontrol bawah $(\mathrm{LCL})=\mathrm{C}-3 \sqrt{ }(2 \& \mathrm{C})$

$$
\begin{aligned}
& =100,33-3 \\
& =100,33-30,05 \\
& =70,28 \mathrm{pcs}
\end{aligned}
$$

Pada control chart kerusakan baling-baling blower diketahui banyaknya produk cacat ( $\mathrm{NN}) 1204$ pcs dengan banyaknya periode (n) 12 bulan.

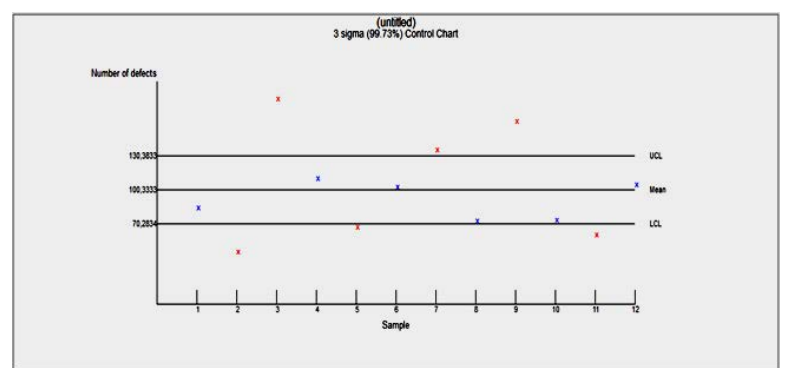

Gambar 5.Control Chart

(Sumber: Data diolah CV. Anugerah Abadi, 2017)

\section{SIMPULAN}

Terdapat lima kecacatan dalam pembuatan baling-baling blower U-8 yaitu cacat berlubang, permukaan kasar, retak, kekasaran meluas dan deformasi. Kecacatan yang dialami sebesar 1204 produk atau 20,27\% dari jumlah produksi. Permukaan kasar merupakan jenis cacat yang mempunya tingkat kecacatan terbesar yaitu $53,08 \%$ dari total kecacatan atau sebanya 627 produk. Dengan 
70 | Sofiyanurriyanti, Analisa Kecacatan Produk Baling-Baling Blower...

demikian cacat permukaan kasar harus segera ditanggulangi. Untuk mengurangi cacat produk baling-baling blower U-8 harus difokuskan pada jenis kecacatan permukaan kasar. Untuk mengurangi jenis kecacatan tersebut operator harus lebih teliti dalam melakukan

tungku peleburan.

\section{DAFTAR PUSTAKA}

Baroto, Teguh. (2002) . Perencanaan dan Pengendalian Produksi. Jakarta: Ghalia Indonesia.

Dorothea, wahyu. (2003). Pengendalian Kualitas Statistik. Yogyakarta: Universitas Gajah Mada.

Gasperz, Vincent. (2005). ISO 9001 : 2000 And Continual Improvement. Jakarta: Gramedia Pustaka Utama.

Gitosudarmo, H.Indriyo. (2002). Manajemen Operasi. Edisi Kedua. Yogyakarta : BPFE Fakultas Ekonomi UGM.

Handoko, T.Hani. 1999. Dasar-Dasar Manajemen Produksi dan Operasi. Edisi Pertama. Yogyakarta : BPFE.

Khadijah, Siti. 2003. Perencanaan Perbaikan Mutu. Medan: Universitas Sumatera Utara.

Momon, Ade. 2012. Implementasi Sistem Pengendalian Kualitas Dengan Metode Seven Tools Terhadap Produk Shotblas Pada Proses Cast Wheel Di PT. XYZ. Karawang: Universitas Singaper- pemeriksan cetakan pasir, bahan baku aluminium juga harus bersih dan sebagian dari bahan ingot(batangan), campuran pasir cetak harus diperhatikan, kondisi lingkungan harus menerapkan 5P dan menambah fasilitas kerja( lampu penerangan), pergantian alat seperti mold dan penambahan pengkur suhu pada

\section{bangsa.}

Purnama, Nursya'bani. 2006. Manajemen Kualitas Prespektif Global. Yogyakarta: Ekonesia.

Render, Barry dan Jay Heizer. 2001. Prinsip-Prinsip Manajemen Operasi. Edisi Pertama. Jakarta :Salemba Empat.

Rocatama, Aditya. 2009. Analisis Pengendalian Kualitas Produk Kain Cotton Dan Rayon $\mathrm{Di}$ Departemen Printing-Dyeing Pada PT.Kusumahadi Santosa. Surakarta: Universitas Sebelas Maret.

Tampubolon, Manahan P. 2004. Manajemen Operasi (Operations Management). Jakarta : Ghalia Indonesia.

Tjiptono, F. dan Diana, A. 2003. Total Quality Management (TQM). Edisi Revisi. Yogyakarta: Andi.

Yamit, Zulian. 2004. Manajemen Kualitas Produk dan Jasa. Edisi Pertama. Yogyakarta : Ekonesia. 